\title{
Situational analysis: preliminary regional review of the Mental Health Atlas 2014
}

\author{
R. Gater, ${ }^{1,2}$ Z. Chew ${ }^{7}$ and K. Saeed ${ }^{3}$
}

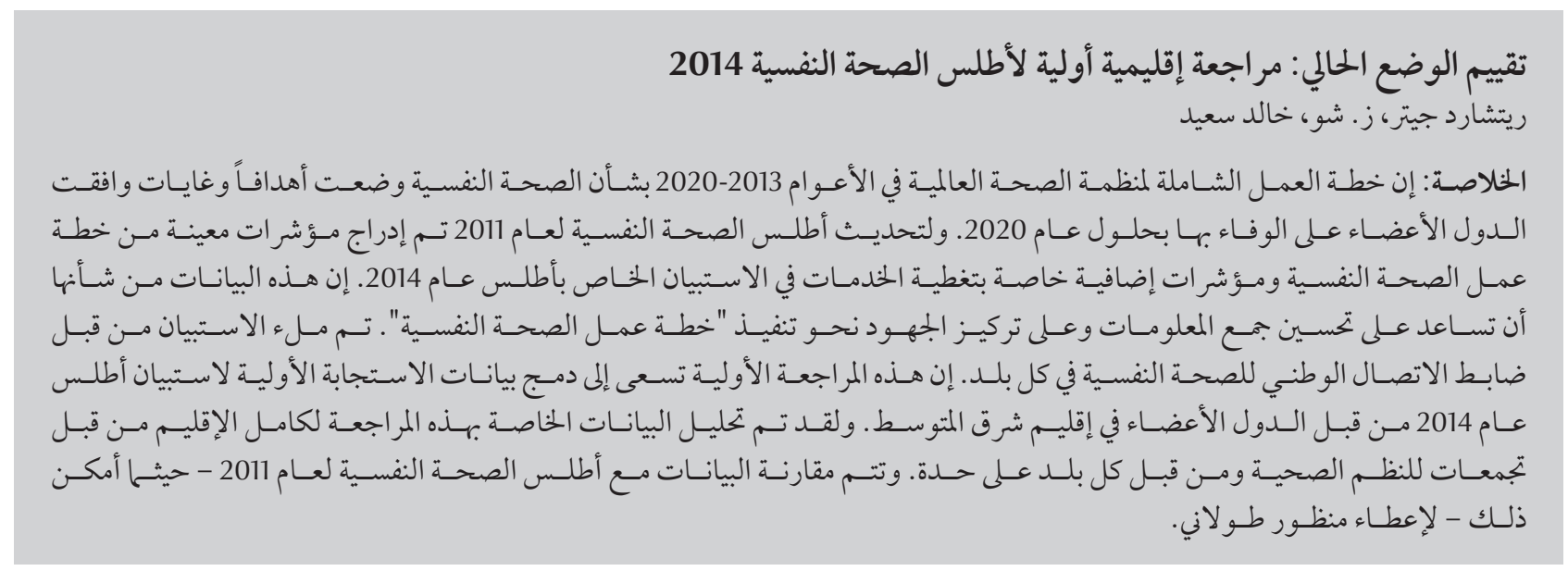

ABSTRACT The WHO comprehensive Mental Health Action Plan 2013-2020 established goals and objectives that Member States have agreed to meet by 2020. To update the Atlas of Mental Health 2011, specific indicators from the Mental Health Action Plan and additional indicators on service coverage were incorporated into the questionnaire for the Atlas 2014. The data will help facilitate improvement in information gathering and focus efforts towards implementation of the Mental Health Action Plan. The questionnaire was completed by the national mental health focal point of each country. This preliminary review seeks to consolidate data from the initial response to the Atlas 2014 questionnaire by Member States in the Eastern Mediterranean Region. Data for this review were analysed for the whole Region, by health systems groupings and by individual countries. Where possible, data are compared with the Mental Health Atlas 2011 to give a longitudinal perspective.

\section{État des lieux : examen régional préliminaire de l'Atlas de la santé mentale 2014}

RÉSUMÉ Le Plan d'action exhaustif de l'OMS pour la santé mentale sur la période de 2013-2020 a déterminé des cibles et des objectifs que les États Membres ont accepté d'atteindre d'ici 2020. Pour actualiser l'Atlas de la santé mentale de 2011, des indicateurs spécifiques du Plan d'action pour la santé mentale ainsi que des indicateurs supplémentaires concernant la couverture des services ont été intégrés au questionnaire pour l'Atlas 2014. Les données permettront de favoriser l'amélioration du recueil d'informations et de concentrer les efforts sur la mise en application du Plan d'action pour la santé mentale. Le questionnaire a été complété par le point focal national pour la santé mentale dans chaque pays. Cet examen préliminaire visait à consolider les données provenant de la réponse initiale au questionnaire pour l'Atlas 2014 par les États Membres dans la Région de la Méditerranée orientale. Les données pour cet examen ont été analysées pour toute la Région, par groupes de systèmes de santé et par pays. Dans la mesure du possible, les données ont été comparées à celles de l'Atlas de la santé mentale de 2011 pour apporter une perspective longitudinale. 


\section{Introduction}

The World Health Organization (WHO) recognizes the increasing burden of mental disorders globally and the huge gap between the need for treatment and the provision of mental health care. Following consultation with representatives of Member States, civil society and international partners, the comprehensive Mental Health Action Plan 2013-2020 was adopted at the World Health Assembly in May 2013. The action plan sets out objectives with specific targets to be achieved by 2020 (1).

The results of a global exercise in mapping of mental health resources in the form of the WHO Atlas of Mental Health was first published in 2001 and updated in 2005 and 2011 (2). The targets and key indicators of the comprehensive Mental Health Action Plan have been incorporated into the latest version of the Atlas 2014 to help focus the planning, development and monitoring of mental health services.

This preliminary regional review is based on the initial responses to the Mental Health Atlas 2014 questionnaire from Member States of the Eastern Mediterranean Region (EMR). This is a step in the ongoing project to gather, clarify and analyse the data from Member States, and as such it is not the definitive report.

\section{Methods}

The Mental Health Atlas 2014 questionnaire was developed by WHO to include specific indicators as identified by the comprehensive Mental Health Action Plan. The WHO Secretariat was also requested to identify additional indicators to expand on the data collected on mental health services provision. The 14 groups of indicators in the Mental Health Atlas are shown in Table 1 , organized according to the objectives of the action plan.

The Regional Office for the Eastern Mediterranean (EMRO) collaborated with the responsible ministries of Member States of the EMR to appoint a local contact for completing the Atlas questionnaire. Once the questionnaire had been completed and submitted back to EMRO, there was a continuing process to clarify incomplete or inconsistent answers with the local contact.

Data were analysed on a regional basis and by individual countries and, where possible, they were also organized according to health system groups, which is a classification of countries into
3 groups based on population health outcomes, health system performances and health expenditure. The latest data were compared with the results from the Mental Health Atlas 2011 when corresponding data were available.

\section{Results}

All 22 Member States of the EMR completed the Atlas 2014 questionnaire. However, there were specific questions for which the country response rates were very low (e.g. with 6 or fewer countries providing data) which renders analysis at the regional level unreliable in some cases.

\section{Mental health policy}

A useful indicator of leadership and governance is the presence and degree of implementation of an updated national mental health policy and information about whether the policy is in line with human rights instruments.

The majority of EMR countries have a stand-alone mental health policy that has been updated in the past 10 years (Figure 1). However, where present, the mental health policies are only partially implemented.

With regards to compliance with human rights instruments, most countries'

\begin{tabular}{|c|c|}
\hline Action plan objective & Indicators included in questionnaire \\
\hline Leadership and governance & $\begin{array}{l}\text { - Mental health policy } \\
\text { - Mental health legislation }\end{array}$ \\
\hline $\begin{array}{l}\text { Comprehensive, integrated and responsive mental health and } \\
\text { social care services }\end{array}$ & $\begin{array}{l}\text { - Stakeholder involvement } \\
\text { - Mental health spending } \\
\text { - Mental health workforce } \\
\text { - Mental health training in primary care } \\
\text { - Service availability and utilization } \\
\text { - Service coverage } \\
\text { - Inpatient care } \\
\text { - Continuity of care after discharge } \\
\text { - Social support }\end{array}$ \\
\hline Promotion and prevention & $\begin{array}{l}\text { - Mental health promotion and prevention } \\
\text { - Suicide rate }\end{array}$ \\
\hline Information systems & - Core mental health indicator set \\
\hline
\end{tabular}




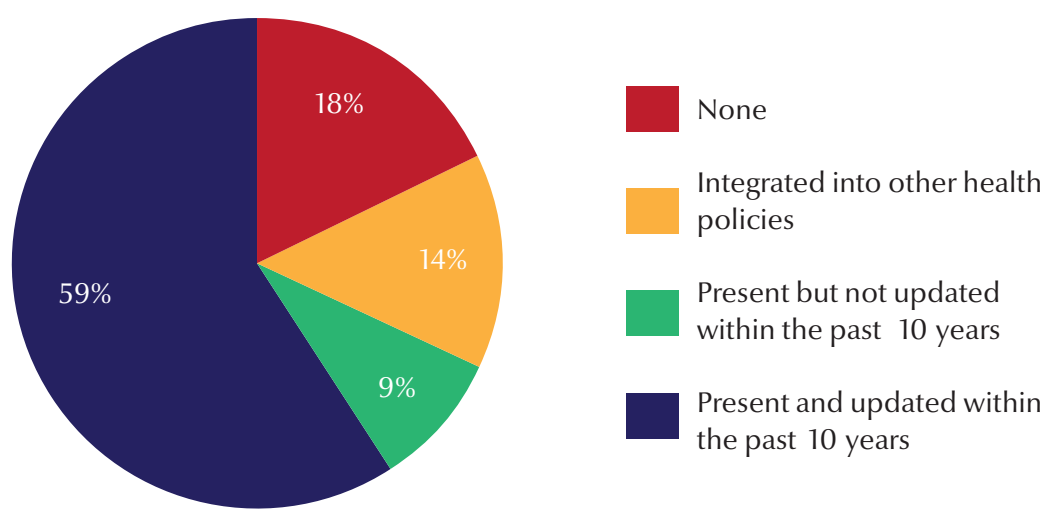

Figure 1 Percentage of Eastern Mediterranean Region countries with a mental health policy (Source: Mental Health Atlas 2014)

policies promote community-based and integrated services $(85 \%)$ and explicitly respect human rights (81\%). More than half promote a full range of services for independent living (62\%). Half of the policies promote a recovery approach (50\%) and less than half promote participation in decision-making processes (43\%).

\section{Mental health legislation}

A similar but distinct indicator of leadership and governance is the presence of contemporary national mental health legislation, its degree of implementation and whether it is in line with international human rights instruments.

Half of the EMR countries (50\%) have stand-alone mental health legislation. However, among these almost half were revised more than 10 years ago; 6 countries have mental health legislation integrated into other legislation; and 5 countries do not have mental health legislation, although one of these is pending ratification. Of the countries with stand-alone and updated mental health legislation, none of them have fully implemented the legislation and only 1 country has partially implemented their mental health legislation, with the remaining countries having legislation available but not implemented (Figure 2).

With regards to compliance with human rights instruments, most EMR countries' legislation promotes rights to exercise capacity and nominate a trusted person to support the patient (65\%), promotes alternatives to coercive practice $(67 \%)$ and provides for protection of patients' rights to file appeals/complaints to independent bodies (65\%). In half of the countries, legislation promotes the transition to mental health services in the community $(50 \%)$ and regular inspection of human rights conditions by an independent body (50\%).

\section{Stakeholder involvement}

Persons with mental disorders and their families are useful crucial sources of information, collaboration and lobbying in relation to the needs of those with mental disorders. The Atlas questionnaire enquired about the degree of stakeholder involvement over the past 2 years in developing national policies in the domains of information, policy, early family involvement, stakeholder participation and resources (Figure 3). Half of EMR countries have at least partial implementation for information, but for the other 4 domains most EMR countries reported that measures of stakeholder involvement are not implemented. In about one-quarter of countries, measures were partially implemented. Full implementation was rarely reported.

\section{Mental health spending}

The financial resources allocated to mental health services are critical for the development of integrated and
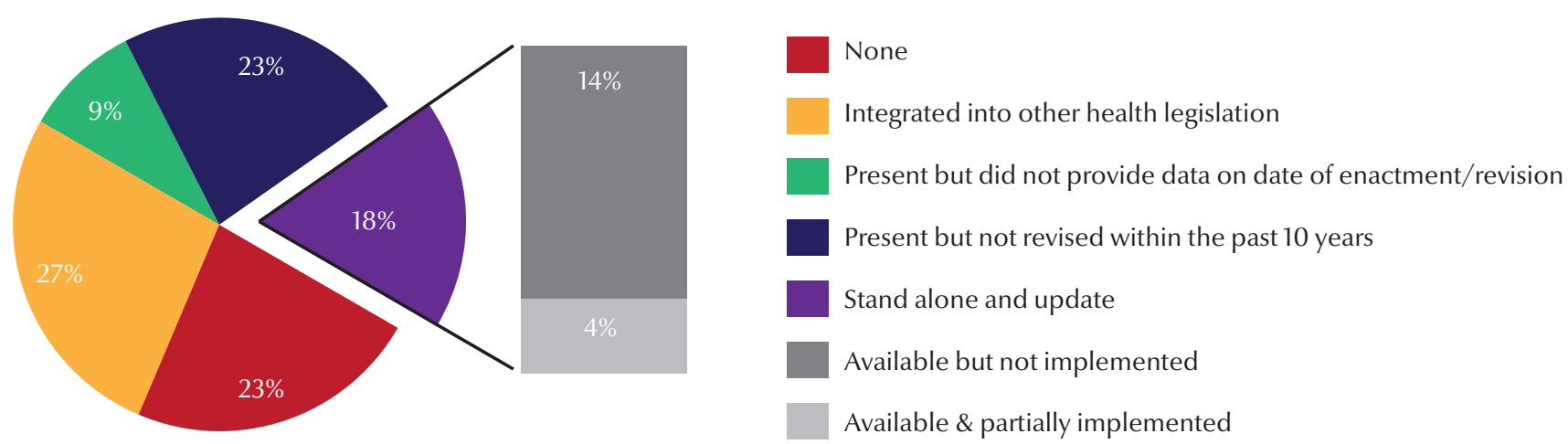

Figure 2 Percentage of Eastern Mediterranean Region countries with stand-alone and updated mental health legislation (Source: Mental Health Atlas 2014) 


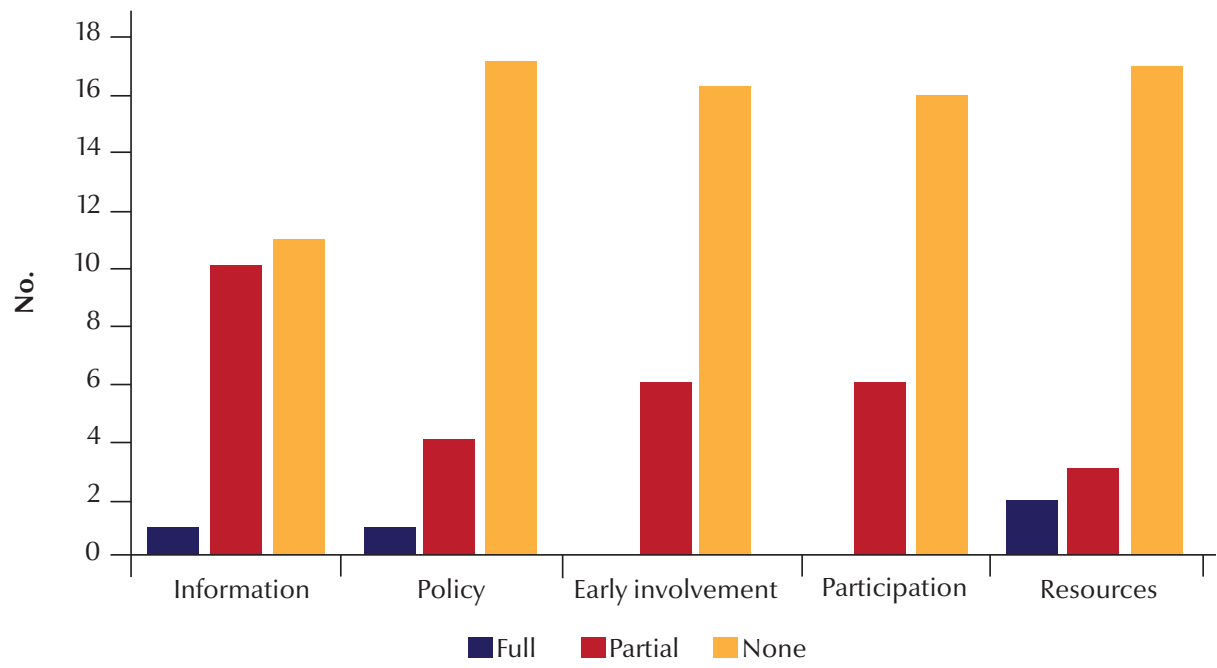

Figure 3 Number of Eastern Mediterranean Region countries reporting on the degree of implementation of stakeholder involvement in development of national policies in different domains (Source: Mental Health Atlas 2014)

comprehensive mental health services. The Atlas questionnaire asked about the main source of funding in countries and how the mental health budget is allocated to the different components of mental health services, ranging from mental health hospitals to communitybased outpatient facilities to social services.

In most countries of the Region the government is the main source of funding (77\%). In the remaining countries, the main source of funding is households ( 2 countries), non-government organizations ( 1 country) or unknown ( 2 countries did not report).

With regards to the allocation of the budget to the different components of mental health services, 9 countries in the Region provided data on their annual spending dedicated to mental health hospitals. Less than 1 in 5 provided data on a specified budget allocated to the other components of mental health services (Figure 4).

Of the 9 countries that provided data on their spending on mental health hospitals, the group 1 countries (Bahrain and Qatar) have the highest per capita expenditure. The 2 countries with the lowest per capita expenditure have households and nongovernmental organizations as their main source of funding, while for the 7 other countries the government is the main source of funding.

\section{Mental health workforce}

The provision of mental health services is dependent on the availability of human resources in the form of trained mental health professionals per 100000 population. There are corresponding data on human resources from the Mental Health Atlas 2011 which allow for a comparison with 2014 (Table 2).

In the latest data, nurses make up the largest professional group in the mental health workforce, followed by other health or mental health workers. There is typically 1 psychologist and psychiatrist for every 5 nurses. Although medical doctors not specializing in psychiatry are relatively uncommon throughout the Region, the upper limit of the range indicates that a small number of countries employ a large number of non-psychiatrist medical doctors. Social workers and occupational therapists are relatively uncommon.

Although there has been an increase in the median number of mental health nurses per 100000 population as a whole, there is actually a reduction in the median of nurses in group 3 countries in 2014 when compared with 2011. Group 1 countries show the highest increase of their nursing workforce, while group 2 countries show a smaller increase. From 2011 to 2014, there was also an increase in the median number of psychiatrists in group 1 countries but a decrease in group 2 and 3 countries.

\section{Mental health training in primary care}

Mental health training in primary care is a useful indicator of the accessibility of mental health care to the population as well as the degree of integration of mental health care into general health care. The Atlas questionnaire collected data on mental health training of at least 2 days duration over the past 2 years for a range of community health-care professionals.

Only half the EMR countries provided data on the proportion of primary care staff receiving mental health training. Less than half of countries provided data on training of the other mental health professionals. Of those that provided data, there is a large range among the countries in the provision of training, with generally low percentages of primary care 


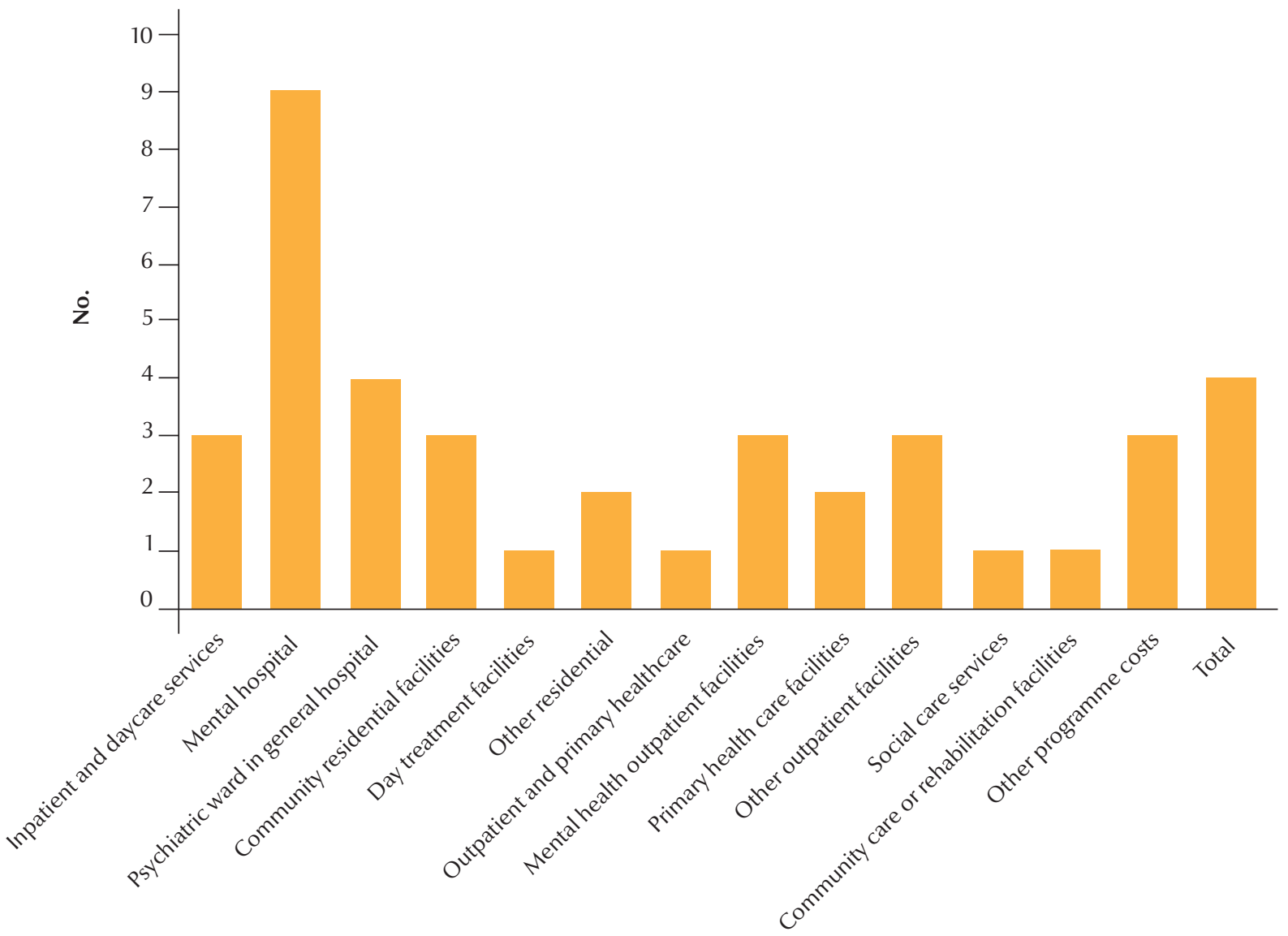

Figure 4 Number of Eastern Mediterranean Region countries reporting on annual government spending on different types of mental health care (Source: Mental Health Atlas 2014)

Table 2 Median number of health professionals per 100000 population in Eastern Mediterranean Region countries in 2011 and 2014 (psychiatrists and nurses were further categorized by the country's health system group)

\begin{tabular}{|c|c|c|c|c|}
\hline \multirow[t]{2}{*}{ Type of health professional } & \multicolumn{2}{|c|}{ Year 2011} & \multicolumn{2}{|c|}{ Year 2014} \\
\hline & Median & Range & Median & Range \\
\hline Psychiatrists & 0.86 & $0.01-8.18$ & 0.77 & $0-5.44$ \\
\hline Group 1 countries & 2.18 & & 2.76 & \\
\hline Group 2 countries & 0.91 & & 0.66 & \\
\hline Group 3 countries & 0.06 & & 0.08 & \\
\hline $\begin{array}{l}\text { Nurses (both psychiatric nurses and general nurses } \\
\text { working in mental health facilities) }\end{array}$ & 3.3 & $0.10-29.12$ & 4.21 & $0-24.70$ \\
\hline Group 1 countries & 10.71 & & 12.89 & \\
\hline Group 2 countries & 2.37 & & 2.99 & \\
\hline Group 3 countries & 0.32 & & 0.12 & \\
\hline Other medical doctors, not specializing in psychiatry & 0.28 & $0.01-13.95$ & 0.15 & $0-50.09$ \\
\hline Psychologists & 0.41 & $0-2.29$ & 0.81 & $0-5.16$ \\
\hline Social workers & 0.47 & $0-3$ & 0.27 & $0-3.02$ \\
\hline Occupational therapists & 0.04 & $0-1.73$ & 0.17 & $0-1.13$ \\
\hline $\begin{array}{l}\text { Other health or mental health workers working in } \\
\text { mental health facilities }\end{array}$ & 4.35 & $0.04-55.53$ & 2.47 & $0-118.47$ \\
\hline
\end{tabular}

Sources: Mental Health Atlas 2011 (1) and Mental Health Atlas 2014. 
staff receiving training in the past 2 years. In all countries, there is provision of some mental health training for medical doctors. However, the percentage of medical doctors receiving such training varies greatly. Other health-care workers receive training in some countries, although the proportion of these staff trained across the Region is considerably lower than that of medical doctors (Table 3).

\section{Service availability and utilization}

Indicators for mental health service provision include the availability of facilities ranging from the number of psychiatric beds across different settings to the number of day-care and outpatient facilities. The Atlas questionnaire included questions about the utilization of outpatient facilities.

A total of 20 countries in the Region reported that they have at least 1 mental health hospital; 14 countries have psychiatric beds in general hospitals and 5 countries have psychiatric beds in community residential facilities. In 2014, the reported distribution of psychiatric beds in mental health hospitals, general hospitals and community settings was $65 \%, 18 \%$ and $17 \%$ respectively. This distribution is largely unchanged from the 2011 distribution of $66 \%, 18 \%$ and $16 \%$ respectively.

There is a wide range in the average number of beds in each level of mental health service. The median number of psychiatric beds in mental health hospitals is 220 (range 14 to 779 ), in general hospitals is 17 (range 3 to 60) and in community residential facilities is 33 (range 6 to 124).

There are 8 countries with mental health day-care or day-treatment facilities. Four countries have only 1 such facility. Of the remaining 4 countries, the median number of day-care facilities is 31 (range 2 to 117). The median number of places in a day-care facility is 10 (range 1 to 46) across the Region.

\begin{tabular}{|c|c|c|c|}
\hline \multicolumn{4}{|c|}{$\begin{array}{l}\text { Table } 3 \text { Number of Eastern Mediterranean Region countries reporting on mental } \\
\text { health training across primary care health-care professionals and the percentage } \\
\text { median number who received training in } 2014\end{array}$} \\
\hline \multirow[t]{2}{*}{ Type of health professional } & \multirow[t]{2}{*}{$\begin{array}{l}\text { No. of countries } \\
\text { reporting on } \\
\text { training }\end{array}$} & \multicolumn{2}{|c|}{$\begin{array}{l}\% \text { of primary care staff who } \\
\text { received training in the past } 2 \\
\text { years }\end{array}$} \\
\hline & & Median & Range \\
\hline Medical doctors & 11 & 29 & 15-99.5 \\
\hline Nurses & 11 & 5 & $0-54$ \\
\hline Midwives & 7 & 2 & $0-58$ \\
\hline Community health workers & 5 & 5 & $0-76$ \\
\hline Other health care workers & 7 & 16 & $0-100$ \\
\hline
\end{tabular}

Source: Mental Health Atlas 2014.

Outpatient facilities are reported by 18 of the countries. The number of such facilities varies widely from 1 in Kuwait to 4356 in Pakistan. The median number of patients seen in a week in mental health outpatient facilities across the Region is 100 .

There is huge variation of the availability of mental health services across the Region. The total number of psychiatric beds per 100000 population has decreased in 2014 as compared with 2011. However, this decrease is only reflected in group 2 countries, whereas group 1 and 3 countries had an increase in their total number of psychiatric beds per 100000 population over the same period. The median number of day-care facilities has increased marginally to 0.008 per 100000 population but still remains 10 times lower the global median in 2011. The median number of outpatient facilities is almost halved in 2014 as compared with 2011 but the number of outpatient visits per week has increased by almost 5 -fold over the same period (Table 4).

\section{Service coverage}

Service coverage is a measure of the number of persons with a mental disorder who received treatment in the past year. The Atlas questionnaire enquired about the total number of persons with mental disorders who received care at the different levels of service and also the mental disorders of those who received care.
The median treated prevalence of mental disorders in hospitals in the Region is about 46 per 100000 population (29 per 100000 population in psychiatric wards of general hospitals and 1116 per 100000 population in outpatient facilities) (Table 5). Therefore, about 1 in every 15 patients seen in outpatients is admitted to a psychiatric bed.

\section{Inpatient care}

The Atlas questionnaire collected data on the length of stay and legal status of persons with mental disorders who were inpatients within the past 1 year.

Ten countries provided data. In the majority of countries, the length of stay is most often less than 1 year. Substantial percentages of persons with a mental disorder staying for 1 to 5 years are reported in Iraq, Syrian Arab Republic, United Arab Emirates and Lebanon, with a range from $28 \%$ to $51 \%$. Stays of more than 5 years occur most frequently in Jordan, United Arab Emirates, Iraq and Lebanon, with a range from $34 \%$ to $56 \%$. Eight of the countries that provided data had a corresponding data-set from 2011. The Islamic Republic of Iran and Pakistan have a similar distribution of lengths of stay in 2011 and 2014. Kuwait, Lebanon and Occupied Palestinian Territories have shorter inpatient stays in 2014 than in 2011. In Jordan, Qatar and Syrian Arab Republic the duration of inpatient stay has increased in between 2011 and 2014 (Figure 5). 


\begin{tabular}{|c|c|c|c|c|}
\hline \multirow[t]{2}{*}{ Variable } & \multicolumn{2}{|c|}{ Year 2011} & \multicolumn{2}{|c|}{ Year 2014} \\
\hline & Median & Range & Median & Range \\
\hline Psychiatric beds in mental health hospitals & 5.4 & $0.38-40.06$ & 4.5 & $0-23.9$ \\
\hline Psychiatrics beds in general hospitals & 0.51 & $0-3.4$ & 0.64 & $0.09-7.3$ \\
\hline $\begin{array}{l}\text { Psychiatric beds in community residential } \\
\text { facilities }\end{array}$ & $\mathrm{n} / \mathrm{a}$ & $\mathrm{n} / \mathrm{a}$ & 1.2 & $0.5-6.8$ \\
\hline All psychiatric beds & 7.0 & $0.73-41.16$ & 6.1 & $0.7-24.2$ \\
\hline Group 1 countries & 8.3 & $\mathrm{n} / \mathrm{a}$ & 10.5 & $1.4-24.2$ \\
\hline Group 2 countries & 7.8 & $\mathrm{n} / \mathrm{a}$ & 6.4 & $1.1-16.7$ \\
\hline Group 3 countries & 3.0 & $\mathrm{n} / \mathrm{a}$ & 4.2 & $0.7-7.3$ \\
\hline Day-care facilities & 0.005 & $0-0.17$ & 0.008 & $0.003-0.44$ \\
\hline Outpatient facilities & 0.28 & $0.035-2.1$ & 0.17 & $0.02-2.4$ \\
\hline Outpatient visits per week & 279 & $\mathrm{n} / \mathrm{a}$ & 1310 & 378-10 614 \\
\hline
\end{tabular}

Sources: Mental Health Atlas 2011 (1) and Mental Health Atlas 2014.

$n / a=$ data not available from published Mental Health Atlas 2011.

The 11 countries which provided data on involuntary admissions to inpatient mental health hospitals reported a median of $26 \%$ of admissions being involuntary (range 0\% to 95\%). Four countries provided data on psychiatric wards in general hospitals that showed a median at $32 \%$ of admissions being involuntary (range $2 \%$ to $71 \%$ ). Only 1 country reported on involuntary admissions to mental health community residential facilities, showing that the proportion was $34 \%$ of admissions.

\section{Continuity of care after discharge}

Follow-up in the community after discharge from psychiatric inpatient settings is a useful indicator of the integration of mental health services into health services across inpatient and community settings.

Only 4 countries provided data on follow-up of patients within 1 month after discharge from psychiatric inpatient settings and, because of the wide range across the different countries, no meaningful data can be compiled at the regional level.

\section{Social support}

Information on the integration of mental health services with social services is provided by data on social support in the community in the form of either monetary or non-monetary support.

There are limited data on the social support received by persons with mental disorders in the EMR. Only 5 countries provided data on the number of persons with mental disorders who received monetary social support in the past year, and only 2 reported on nonmonetary support.

\section{Mental health promotion and prevention}

A total of 21 countries provided information on the presence and implementation of national mental health promotion and prevention

\begin{tabular}{|c|c|c|c|}
\hline Care setting/type of mental disorder & $\begin{array}{l}\text { No. of countries reporting } \\
\text { on coverage }\end{array}$ & Median & Range \\
\hline \multicolumn{4}{|l|}{ Mental hospitals } \\
\hline All mental disorders & 13 & 46 & $4-1151$ \\
\hline Non-affective psychoses & 6 & 12 & $3-47$ \\
\hline Bipolar disorders & 6 & 1 & $0.2-38$ \\
\hline Moderate to severe depression & 6 & 10 & $0.1-77$ \\
\hline \multicolumn{4}{|l|}{ Psychiatric ward in general hospitals } \\
\hline All mental disorders & 9 & 29 & 0-1017 \\
\hline \multicolumn{4}{|l|}{ Mental health outpatient facilities } \\
\hline All mental disorders & 8 & 1116 & $37-3810$ \\
\hline
\end{tabular}

Source: Mental Health Atlas 2014. 


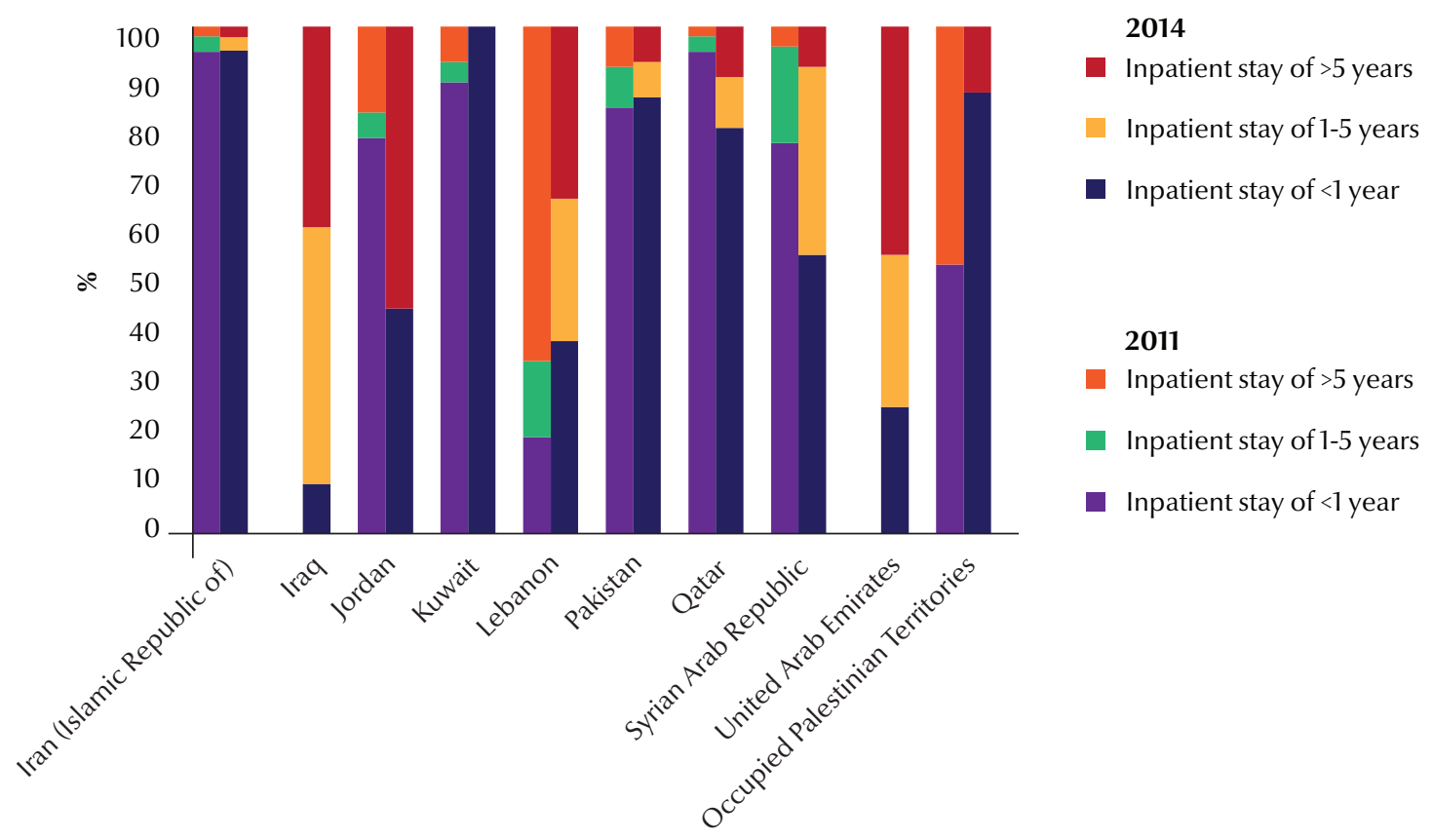

Figure 5 Percentage of inpatients with duration of stay $<1$ year, 1-5 years and $>5$ years in the Eastern Mediterranean Region countries [Sources: Mental Health Atlas 2011 (1) and Mental Health Atlas 2014]

programmes. Promotion and prevention programmes are present in 15 countries in the Region (Figure 6). Countries with 10 or more programmes include members of each of the 3 EMR health system groups.

\section{Suicide rate}

The Atlas questionnaire asked about the existence of suicide prevention strategies at national, regional and local level in each country as well as the crude suicide rate.

Of the 21 countries who reported on this indicator, only 4 countries have national suicide prevention strategies. Only 5 countries were able to provide data on suicide rates.

\section{Core mental health indicator set}

The collection of mental health data is important to inform and focus planning and implementation towards the goals of the WHO comprehensive Mental Health Action Plan. The Atlas 2014 questionnaire to countries in the Region asked about the collection of mental health data and the reporting of these in a mental health report.
Dedicated mental health reports have been produced in half of the countries in the Region in the past 2 years. Most other countries have reported mental health data only in general health statistics. Two countries did not compile a mental health report in the past 2 years and 1 country did not report on this indicator.

\section{Summary of key findings}

1. Mental health policy: Most EMR countries have updated mental health policies but these are only partially implemented. In many countries there remains a need to review and revise mental health policy in line with internationally agreed human rights instruments.

2. Mental health legislation: Most EMR countries have stand-alone mental health legislation and about half of them have revised legislation in the past 10 years. Most of the countries with updated stand-alone mental health legislation have not imple- mented it. Although aspects of existing legislation were compliant with human rights instruments in most countries, there remains a need for further review and revision.

3. Stakeholder involvement: Stakeholder involvement is underdeveloped in almost all EMR countries. This represents an important opportunity to develop partnerships to catalyse and influence change and improvement in the planning and delivery of mental health services.

4. Mental health spending: The majority of countries in the EMR have not reported specific data on mental health spending, which suggests a lack of a specific budget for mental health. Mental health spending is lowest in countries where the government is not the main source of funding.

5. Mental health workforce: There has been a greater increase in 2014 in the supply of psychiatrists and nurses in group 1 countries as compared with group 2 and group 3 countries and this could represent an increased investment in the mental health workforce in these countries. 


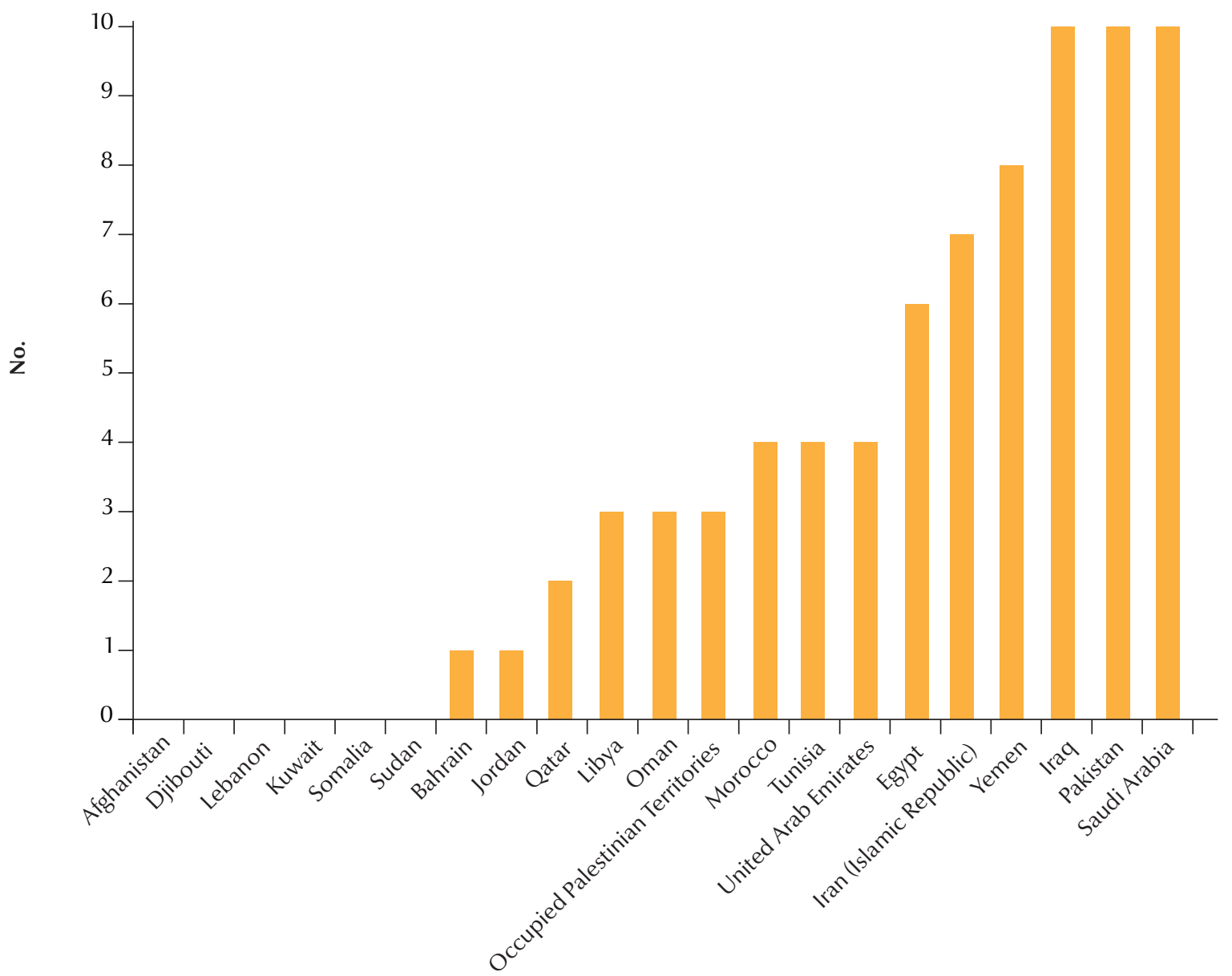

Figure 6 Number of mental health promotion and prevention programmes reported by Eastern Mediterranean Region countries (Source: Mental Health Atlas 2014)

There is a suggestion from the data that key components of the mental health workforce have fallen in group 3 countries.

6. Mental health training in primary care: Less than half of EMR countries report comprehensively on training for primary care staff on mental health. There is considerable variation on training received by health-care professionals, but overall the median rate of in-service training across the Region is low.

7. Service availability and utilization: There is very great variation in the provision of mental health-care facilities in different countries across the Region. The distribution of psychiatric beds remains largely unchanged from 2011 but the total number of beds per 100000 population has reduced. The availability of mental health day-care or day-treatment facilities remains 10 times lower than the global average reported in 2011. The number of outpatient facilities has decreased from 2011 but there has been an increase in the number of outpatient visits.

8. Service coverage: Information on service coverage is limited in the Region. Few countries were able to provide comprehensive data about people with mental disorders who have received care.

9. Inpatient care: There are limited data on inpatient care from countries in the Region, with less than half of all countries providing comprehensive data. Among the countries that provided data, there was a reduction in the length of hospital stay in some of them, which may be a positive indicator of the development of community mental health services in these countries.

10. Continuity of care after discharge: There are limited data on the follow-up of patients after discharge from inpatient care and this could indicate a lack of governance structures for the transition of care to community settings.

11. Social support: Limited data on the provision of social support in the community across the Region may indicate that there is potential for the increased integration of social support systems with mental health services across the EMR.

12. Mental health promotion and prevention: There is a wide range in the num- 
bers of promotion and prevention programmes; this appears to be irrespective of a country's level of development or wealth as represented by the health system grouping. More than one-quarter of countries in the Region have not yet started to address mental health promotion and prevention programmes.
13. Suicide rate: Suicide rates are poorly reported across the Region and a majority of countries do not have any suicide prevention strategy in place. This presents an opportunity for the development of prevention strategies (3).

14. Core mental health indicator set: Although almost all EMR countries re- ported having captured and reported on mental health data over the past 2 years, this regional analysis suggests that there are gaps in the data collection and that current information systems may not be in line with target indicators of the comprehensive Mental Health Action Plan and Mental Health Atlas.

\section{References}

1. Mental health atlas 2011. Geneva: World Health Organization; 2011 (http://whqlibdoc.who.int/publications/2011/9799241564359_eng.pdf?ua=1, accessed 19 May 2015).

2. Mental health action plan 2013-2020. Geneva: World Health Organization; 2013 (http://apps.who.int/iris/bitstre am/10665/89966/1/9789241506021_eng.pdf, accessed 19 May 2015).

3. Preventing suicide: a global imperative. Geneva: World Health Organization; 2014 (http://apps.who.int/iris/bitstre am/10665/131056/1/9789241564779_eng.pdf?ua=1\&ua=1, accessed 19 May 2015). 